\title{
Correspondence
}

\section{Academy reform needs a reality check}

Government reform of the Russian Academy of Sciences is timely (Nature 499, 5-6; 2013). But it must also be realistic. Simply imposing foreign models could be costly, inefficient and have disastrous consequences for the country's scientific community.

The Russian government contends that the academy is inefficient, so we suggest an international audit of its output. The results could then be compared with those of recent, costly government initiatives to commercialize science, such as the nanotechnology firm Rusnano and the Skolkovo Innovation Center near Moscow.

The government has a poor record of agency reforms: at the defence ministry, for example, changes triggered corruption, sale of the property to private investors and degradation of the army. We propose a moratorium on changes to the academy's buildings to prevent its arbitrary closure.

The proposal to merge the academy with other minor academies in Russia, which differ in their aims and scientific potential, could result in a lower scientific status for members and an over-representation of the biomedical sciences. If the merger goes ahead, members would still need to be selected on the basis of scientific merit alone.

The Russian Foundation for Basic Research could be given a major role in funding the merged academy's research, which would be better than creating a relatively unstructured government agency.

In our view, publications and other impact-based criteria used to evaluate the productivity of individual scientists and research teams should involve the Russian and the international scientific community.

A demand for rapid innovation must be underpinned by fundamental science. Lessons can be learned from 1948, when the government followed up agronomist Trofim Lysenko's empty promises to improve agriculture and effectively destroyed Soviet genetics, one of the world's best genetics schools. Sergey V. Razin Institute of Gene Biology, Russian Academy of Sciences; and Lomonosov Moscow State University, Moscow, Russia.

Yegor S. Vassetzky Institut Gustave Roussy (CNRS UMR8126), Villejuif, France. vassetzky@igr.fr

\section{Two more red flags for suspect work}

I suggest two more 'red flags' in addition to the six that $\mathrm{C}$. Glenn Begley identifies for evaluating preclinical studies (Nature 497, 433-434; 2013). These extend Begley's question regarding the suitability of statistical tests, and apply particularly to computational analyses of large amounts of data - such as those generated by high-throughput proteomics experiments.

The first new flag concerns the application of a multiplehypothesis correction. The large number of statistical comparisons made in highthroughput data analyses will inflate estimates of significance by increasing the probability that an individual result at a particular significance could occur by chance.

Essentially, this extends the question, "how likely is it that the difference I observe in one measurement is a chance finding?" to the populationlevel question "how likely is it that I would find this difference by chance if I were to look at a whole bunch of measurements?" An example would be to assume that the chances of finding a left-handed player on a basketball team would simply be around 10\% the chance that an individual is left-handed. The real probability would be higher because many players are being tested.

The second flag questions whether an appropriate background distribution was used. It is vital to choose a set of variables appropriate to the question that the experimental results are being tested against for significance. An inappropriate choice of background can artificially induce significance in the results or mask real results. An example would be to sample a women's basketball team to determine whether there is a significant height difference between men and women. Jason E. McDermott Pacific Northwest National Laboratory, Washington, USA. jason.mcdermott@pnnl.gov

\section{Promotional tactics corrupt research}

With more than US\$1 trillion spent globally on research and development in 2007 (see go.nature.com $/ 5 w d d 9 p$ ), sheer scale seems to be corrupting the scientific enterprise as individuals take ever more extreme measures to stand out.

For instance, parliamentary reviews of the 2009 'Climategate' scandal at the University of East Anglia in Norwich, UK, reported evidence of scientific misconduct (see go.nature.com/d6bdco). The allegations included questionable journal refereeing to promote a particular scientific line (see also Nature http://doi.org/ftb9hc; 2010). Instead, journals should be supported as places where unsettled science is refined by open debate. But, compared with 30 years ago, they do seem less willing to publish negative results or cautionary reviews that temper unbridled enthusiasm perhaps because of ratings wars.

In another example, a

May 2011 article in Times

Higher Education reported on the cover-up of data that would otherwise have prevented a cancer drug from entering phase III clinical trials, raising and dashing patients' hopes and putting lives at risk on a false premise.

There is also a tendency to issue breathless press releases to accompany publication of even modest advances, and for entries in the 'future impact' section of grant application forms to be loaded with ludicrous hyperbole.

It is any wonder that trust in scientists is starting to decline (see go.nature.com/3xdcoy)? Michael Kelly University of Cambridge, UK. mjk1@cam.ac.uk

\section{Don't do big-data science backwards}

Large open-access data sets offer unprecedented opportunities for scientific discovery - the current global collapse of bee and frog populations are classic examples. However, we must resist the temptation to do science backwards by posing questions after, rather than before, data analysis.

A scant understanding of the context in which data sets were collected can lead to poorly framed questions and results, and to conclusions that are plain wrong. Scientists intending to make use of large composite data sets need to work closely with those responsible for gathering the data. Standard scientific principles and practice then demand that they first frame the important questions, then design and execute the data analyses needed to answer them. David B. Lindenmayer Australian National University, Canberra, Australia. david.lindenmayer@anu.edu.au Gene E. Likens University of Connecticut, Storrs, USA.

CONTRIBUTIONS

Correspondence may be sent to correspondence@ nature.com after consulting the author guidelines at go.nature.com/cmchno Alternatively, readers may comment online: www.nature.com/nature. 